\title{
Mechanisms of Developing Inclusive Education for Children with Disabilities in Uzbekistan
}

\author{
AlimovaShakhnoza Khamidovna ${ }^{1}$,ZayniddinovaVasila \\ Bakievna $^{2}$, RaximovaShakhnozaAnvarovna ${ }^{3}$, KarimovaGulchekhraAbdukarimovna $^{4}$ \\ ${ }^{1}$ Senior Lecturer, Tashkent University of Information Technologies named after Muhammad al-Khwarizmi, \\ Department of "Humanities", \\ ${ }^{2}$ Senior Lecturer, Tashkent University of Information Technologies named after Muhammad al-Khwarizmi, \\ Department of "Humanities", \\ ${ }^{3}$ Senior Lecturer, Tashkent University of Information Technologies named after Muhammad al-Khwarizmi, \\ Department of "Information Library Systems", \\ ${ }^{4}$ Assistant, Tashkent University of Information Technologies named after Muhammad al-Khwarizmi, \\ Department of "Humanities",
}

\begin{abstract}
The article describes the reforms being carried out in Uzbekistan to bring up mentally retarded people with a broad outlook, especially in the education of children in need of social protection, a part of our society, the issues of education of children with disabilities provided by the Law "On Education" given.Also, some problems and suggestions on the problems of socio-psychological adaptation of children with disabilities in the process of education and ways to overcome them, the introduction of inclusive education for children with disabilities in Uzbekistan, its advantages, main stages, further improvement of inclusive education.

Keywords: children's rights, social protection, disability, integration, inclusive education, individual education, socialization, rehabilitation of children with disabilities, socio-psychological adaptation, psychological training.

Article Received: 16th October, 2020; Article Revised: 30th December, 2020; Article Accepted: 08th January, 2021
\end{abstract}

\section{Introduction}

At a time when the education of children with special needs is becoming one of the most pressing issues, a number of measures are being taken in Uzbekistan to provide social support, rehabilitation, effective development of education, integration into the general education system and inclusive education. - measures are being implemented.In order to implement the system of continuing education in the concept of inclusive education, the Ministries of Public Education, Higher and Secondary Special Education and other administrative bodies support the introduction of inclusive education.

\section{Reforms in the education of children in need of social protection in Uzbekistan}

In order to bring up mentally mature people with a broad outlook, in our country, consistent reforms are being carried out, especially for the education of children in need of social protection, who are part of our society. Based on the universally recognized provisions of international law, the national legal framework for the rights of the child has been radically updated.Our country, which acceded to the Convention on the Rights of the Child on December 9, 1992, has recognized the document adopted by the international community, as well as the recognition of the rights of the child as a supreme value [1]. After joining an important international document on the rights of the child, the implementation process in our country began, ie the reform of legislation in accordance with the requirements of the Convention.

Recognition of the need to pay special attention to the issue of social protection of children with disabilities in Uzbekistan, a sharp change in the focus on their education and future self-development is one of the urgent tasks of our state. An inclusive education policy is being implemented to ensure that people receive education in the special or general education system according to their abilities.In order to implement this policy, 
large-scale reforms, a number of facilities, benefits and conditions for people with disabilities are being created in our country.

The main document that defines the legal basis of education in our country is the Law of the Republic of Uzbekistan "On Education".According to Articles 9, 15, 20 of Chapter 2 of the Law of the Republic of Uzbekistan "On Education", adopted by the Legislative Chamber on May 19, 2020 and approved by the Senate on August 7, 2020, children with disabilities in state specialized educational institutions, general secondary and secondary special education inclusive education or individual study at home, as well as equal opportunities for all students to study in educational institutions, taking into account the diversity of educational needs and individual opportunities on the basis of inclusive education. According to Article 20 of this Law, inclusive education is organized in educational institutions for children (individuals) with physical, mental, sensory (sensory) or mental disabilities, and the procedure for organizing inclusive education is determined by the Cabinet of Ministers of the Republic of Uzbekistan [2].

Issues related to education and vocational training of persons with disabilities are considered in more detail in the draft Resolution of the President of the Republic of Uzbekistan ID-17141 "On measures to further improve the system of education for children with disabilities."In accordance with this decision, from September 1, 2021 in the Republic of Karakalpakstan, regions and the city of Tashkent on a pilot basis in one secondary school to open basic correctional classes for children with various developmental disabilities and in need of treatment and rehabilitation.Also, the establishment of specialized vocational schools for people with disabilities in the regions (in 3 regions) for graduates of 9th grade of specialized educational institutions, vocational training for students of 10-11 grades in specialized educational institutions, the creation of a wide range of conditions for future employment in their future professions, based on their interests and abilities, the provision of these educational institutions with the necessary equipment and raw materials for the teaching of relevant professions [3].

The draft Resolution clearly states that the goal of the Concept for the Development of Inclusive Education in Uzbekistan until 2030 is to create an inclusive education system for children with disabilities in Uzbekistan, to ensure the right of every child with disabilities to inclusive education [4].

The policy on the development of integrated (inclusive) education in Uzbekistan is based on the following principles:

$>$ recognition of integrated (inclusive) education as an important factor in the sustainable development, rehabilitation, social adaptation and integration of children with disabilities;

$>\quad$ integration of all strategic forces, governmental and non-governmental structures, the general public in order to maintain and develop integrated (inclusive) education;

$>\quad$ Openness of integrated (inclusive) education for all, adaptation of the education system taking into account the developmental potential, specific features and educational needs of students;

creation of mechanisms for management and coordination of activities of educational institutions, parents, public organizations in order to integrate children with disabilities into general education;

$>$ Development of special curricula, educational and methodological complexes for integrated (inclusive) educational institutions;

Establishing in students a positive relationship with others, peers, the development of communication and tolerance in others;

$>$ Government support for children with disabilities in receiving quality 
education focused on their needs and capabilities.

Creating the necessary conditions for the education of children and adolescents with disabilities, their emotional and social status, as well as improving the level of education. Therefore, in the system of inclusive education in Uzbekistan, special attention is paid to addressing the following goals and objectives:

$>$ to create the necessary psychological and pedagogical, correctional conditions for the education of children and adolescents with disabilities in the educational institution, to implement mental development and social adaptation through the implementation of general education programs and correctional work aimed at their opportunities;

Ensuring the right of students to equality in education;

$>\quad$ Disabled and healthy with active participation of society and family meeting the needs of children, early in social life adaptation;

realization of the right of children and adolescents with disabilities to live without separation from families;

$>\quad$ To form a friendly and loving attitude towards children and adolescents with disabilities in the society.

Involvement of children with disabilities in education, whether in special schools, preschools, classrooms or groups in general education institutions, or in homes - is a process of integration, because during and after school also that these children interact with other children, including those studying in secondary schools, ensuring their social adaptation and adaptation to society.However, it is the right of every child and parent to choose the appropriate conditions for education. Therefore, the specialists of the psychological-medical-pedagogical commission are responsible for studying the mental and physical condition of the child and the task of diagnosis is assigned, and as a result of a comprehensive examination of the child is required to develop recommendations for teaching children and to determine the appropriate educational conditions for them.

Hundreds of children with disabilities are educated in special boarding schools operating in our country. While all conditions are adequate for children in special schools, there are still gaps. For example, a child may have problems with his or her interactions with the outside world, his or her lack of self-confidence may always justify doing something, and he or she may develop the notion that he or she is disabled or unhealthy.In fact, even if a child is really unhealthy, it is possible to bring him up in a healthy spirit, with the opportunity to be educated on an equal footing with all. It is not a disability that "holds" a person, but how society treats him. The individual abilities, life experiences, support of relatives and social workers are important to overcome the difficulties that arise. Parents' attention should be focused on its content, not on the form of work to be carried out [5.5354].

Inclusive education is an education system that is individualized and adaptable to the needs and care of children and young people with special needs. These studies work with healthy children to correct deficiencies in children studying in secondary schools with the help of special educators and psychologists. Inclusive education allows children with physical or mental disabilities to receive education together with healthy peers.

Based on these ideas, the project "General Education for Children with Disabilities" the process of inclusive education has been implemented in our country since 2007 [6]. The purpose of this project is to ensure that children with special needs receive a full education in secondary schools, to create the necessary conditions for each child with special needs in educational institutions, and to achieve these goals the following tasks have been identified:

Organization of a special
commission for pedagogical and


psychological study of children with special needs;

> Organization of joint medical, social and correctional services;

$>\quad$ Organization of training sessions, seminars and trainings for parents on prevention and rehabilitation in the family and community;

Provision of methodological assistance to parents in the upbringing and intellectual development of children with disabilities;

$>$ Development of correctional and pedagogical methods for teachers of inclusive education and methodological recommendations for their application [7.76-77].

In the process of inclusive education, great demands are placed on secondary school teachers. The reason is that in this process, unlike usual, there are differences in the mental and physical condition of the students. In the process, the teacher must have mastered such skills as how to explain a lesson to a mentally retarded child, and what methods to apply to a hearing-impaired student. Therefore, secondary school teachers are required to update and enrich their knowledge in science for each category of disabilities (mentally retarded, blind, deaf, hard of hearing, disabled).

\section{The main stages of the transition to inclusive education}

The transition to inclusive education will take place in several stages:

The first step is to adapt the school. That is, the school environment should be similar to the physical and mental condition of each child.For example, there should be comfortable exit corridors for children with disabilities, and desks adapted to their condition. Classrooms, kitchens and other areas should be built with convenience for children with special needs. You will also need hearing aids for deaf students, magnifying glasses for blind children, and teaching aids. In short, the school must be enriched to the extent that it can fill the various shortcomings of the children;

$>\quad$ The second stage is teacher training. The method of individual teaching is very important in inclusive education. That is, the teacher must be well aware of the needs, abilities, and shortcomings of each student. Therefore, she deals with each child individually throughout the lesson. He must have mastered the methods used in teaching speech to children with hearing impairments, blind children. In the individual approach, the teacher should be more involved with children with disabilities and also use tools to help them. This requires sending teachers to inservice training;

The third stage - it is very important for students to be friendly to new children with disabilities, to lend them a helping hand. There should be no such things as discriminating against each other, laughing at each other. Explanatory work should be carried out among students so that they can help a friend who is deaf, blind or mentally retarded during the lesson;

$>\quad$ The fourth stage - after such preparation in school, children can be transferred from special boarding schools to ordinary schools. If, indeed, children are sent to ordinary schools after such preparation and adaptation, they will have no difficulty.

Educated on the basis of inclusive education, children learn to serve themselves by playing side by side with their healthy friends, participating in classes, various activities. Most importantly, their desire to be healthy peers helps them develop confidence in the future, social adaptation traits.

In our opinion, the creation of an inclusive environment in schools should be mandatory by the state. Children with disabilities are citizens of Uzbekistan and have the right to education, among others. It is especially important for children to receive a quality education. As of 2019, 
609,000 of the nearly 710,000 disabled citizens are over the age of 16 , and only 10 percent of them have higher education. As can be seen, there are very few disabled citizens with higher education. However, one of the main conditions for poverty reduction is higher education.Education for people with disabilities is a living tool. They will have less opportunity to engage in physical labor, so they will have the opportunity to earn an income through quality education and higher education.

\section{Conclusion}

It is our great achievement that this educational process, which has been established all over the world, is developing in our country today. With this, we will have discovered many more talented young people. Disability does not mean failure. Therefore, it is possible to bring them to the level of an individual by creating many opportunities for all children studying in special boarding schools. Therefore, given the fact that there are some problems in the development of inclusive education for children with disabilities, it is advisable to implement the following tasks:

$>$ Improving the legal and medical knowledge of families with disabilities on inclusive education;

\section{References}

[1] Resolution of the Supreme Council of the Republic of Uzbekistan dated December 9, 1992 No. 757-XII "On accession to the Convention on the Rights of the Child".

[2] Law of the Republic of Uzbekistan "On Education" (New edition) - T.: 2020.

[3] Draft Resolution of the President of the Republic of Uzbekistan dated April 28, 2020 "On measures to further improve the system of education of children with disabilities" ID-17141.

[4] Inclusive education in Uzbekistan Development Concept until 2030.T.: April 28, 2020

[5] Xuxleva

O.V. Shkolnayapsychologicheskayaslujba. M .: Genezis, 2008. P.53-54.
$>$ Establish cooperation between community activists, the public, educational institutions and health workers in creating adequate conditions for the development and rehabilitation of children with disabilities;

Further improve the adaptation and improvement of educational, medical and cultural institutions and services to ensure that children with disabilities have free access;

$>$ Improving the optimal and favorable conditions for the physical, intellectual and spiritual development of children with disabilities;

$>\quad$ Frequent open days, roundtables, psychological trainings with the participation of parents, community activists, psychologists and other specialists to further intensify the educational work in inclusive educational institutions.

A rational society does not give up any, even the smallest factor, on the path of development. Instead, try to use all factors wisely. As children with disabilities form a part of our society, their talent, rational use of potential, will inevitably have a significant impact on the development of our country.

[6] The order of the Ministry of Public Education of the Republic of Uzbekistan from September 11, 2007 of No. 238.

[7] ShomaxmudovaR.Sh. Inclusive education (International and Uzbek experience) .- $\mathrm{T} .: 2011, \mathrm{P} .76-77$.

[8] lex.uz

[9] gov.uz

[10] new.tdpu.uz 